\title{
Prasangka Terhadap Etnis Tionghoa di Pariaman
}

\author{
Putri Novita Sari, Susi Fitria Dewi \\ Prodi Pendidikan Pancasila dan Kewarganegaraan \\ Universitas Negeri Padang \\ E-mail: Putrinovitasari97.sari@gmail.com
}

\section{ABSTRAK}

Artikel ini bertujuan untuk mengetahui bentuk prasangka dan sebab prasangka masyarakat Pariaman terhadap enis Tionghoa. Penelitian ini menggunakan pendekatan kualitatif historis dengan informan 15 saksi hidup masa etnis Tionghoa di Pariaman yang dipilih secara purposive sampling. Data penelitian dikumpulkan dengan wawancara dan studi kepustakaan dengan langkah-langkah pengelolahan data kualitatif. Hasil penelitian menunjukan ada tiga bentuk prasangka masyarakat Pariaman adalah stereotip terhadap etnis Tionghoa sebagai pengkhianat bangsa, stereotip sebagai etnis yang culas, pelit dan tamak dalam perdagangan (ekonomi). Sedangkan penyebab prasangka masyarakat Pariaman terhadap etnis Tionghoa diantaranya pengkhianatan pada kependudukan Jepang, persaingan ekonomi dan perbedaan agama serta sosialkulturnya. Apabila seseorang memiliki prasangka terhadap suku, etnis dan agama tertentu maka tidak akan tercipta komunikasi lintas budaya yang efektif. Mengatasi hal tersebut beberapa upaya yang dapat dilakukan oleh suatu masyarakat untuk meminimalisir prasangka terhadap kelompok masyarakat yang berbeda suku, etnik dan agama adalah dengan tidak menilai seseorang berdasarkan prasangka yang dimilkinya, menciptakan komunikasi antar budaya yang efektif dan keterbukaan dalam menerima perbedaan.

Kata Kunci: prasangka, masyarakat Pariaman, etnis Tionghoa

\section{ABSTRACT}

This article aims to explain the causes of prejudice and the prejudice of the Society of Pariaman against Chinese ethnic. The research used a qualitative approach with the informant of 15 living witnesses of the Chinese ethnic period in Pariaman chosen purposive sampling. Research data is collected with interviews and literature studies with the processing steps of qualitative data. The results showed that there while the form of prejudice of Pariaman society is stereotypical against Chinese ethnic as a traitor of the nation, stereotypes as an dishonest ethnic, stingy and greedy in trade (economics). Three causes of the prejudice of Pariaman against Chinese ethnic, including betrayal of the Japanese occupation, economic competition and religious and socialistic differences. If a person has a prejudice against a certain tribe, ethnicity, and religion it will not create effective cross-cultural communication. Overcoming that some efforts can be made by a community to minimize prejudice against different ethnic groups, ethnic and religious people is not to judge a person based on the 
prejudice that he create effective intercultural communication and openness in accepting the difference.

Keywords : : prejudice, Pariaman society, Chinese

This work is licensed under the Creative Commons Attribution-ShareAlike 4.0 International License. (C)2020 by author.

\begin{tabular}{lll}
\hline Received: Agt 272019 & Revised: Sep 6 2019 & Accepted: Jun 112020 \\
\hline
\end{tabular}

\section{PENDAHULUAN}

Etnis Tionghoa merupakan 1,2\% dari 273 juta populasi total Indonesia (Badan Pusat Statistik (BPS) 2010). Keberadaan Etnis Tionghoa di Indonesia dalam jumlah sedikit (minoritas) ternyata mampu memberikan pengaruh signifikan terhadap masyarakat Indonesia. Adapun pengaruhnya terlihat dalam beberapa aspek seperti ekonomi, budaya, politik dan agama, namun pengaruh tersebut belum diterima baik sepenuhnya oleh masyarakat Indonesia. Hal ini dikarenakan adanya stereotip, prasangka dan diskriminasi yang di alami etnis Tionghoa di Indonesia. Ketertarikan penulis dengan tema artikel ini karena banyaknya etnis Tionghoa di Indonesia mengalami prasangka, stereotip bahkan diskriminasi oleh masyarakat Indonesia di berbagai daerah. Dengan adanya prasangka, stereotip dan diskriminasi antar kelompok dalam masyarakat maka tidak tercipta komunikasi lintas budaya yang efektif. Hal ini juga dapat memicu terjadinya konflik di tengah masyarakat. Oleh karena itu penulis ingin menggali lebih dalam lagi mengenai prasangka terhadap etnis Tionghoa.

Berdasarkan hasil penelitian terdahulu yang dilakukan oleh Burhan (2013) menunjukan bahwa adanya prasangka warga pribumi terhadap etnis Tionghoa yang disebabkan karena mereka terlalu mendominasi perekonomian dan memegang banyak kekuasaan di kota Medan. Hal serupa juga ditemukan dalam penelitian terdahulu oleh Juditha (2015) adanya sterotip dan prasangka terhadap etnis Tionghoa yang disebabkan karena adanya kecemburuan sosial masyarakat setempat. Etnis Tionghoa pendatang yang menguasai pasar atau perekonomian. Penelitian oleh Khoiri (2020) menyatakan bahwa etnis Tionghoa menguasai perekonomian dan transaksi ekonomi di wilayah perbatasan.

Begitu juga dengan penelitian yang dilakukan oleh Murdianto (2018) ditemukan sebab stereotip dan prasangka terhadap etnis Tionghoa yang disebabkan karena menguasai sektor ekonomi "economic animal", orientasi politik dengan asal usul etnis Tionghoa, isu nasionalisme, keraguan kesetian etnis Tionghoa kepada bangsa Indonesia dan budaya etnis Tionghoa yang berbeda dengan budaya orang indonesia yang beragama islam, khususnya dalam makanan seperti babi yang sangat tabu bagi muslim serta pemujaan leluhur yang menyalahi ajaran agama. Hal yang sama ditemukan dalam penelitian farabi (2010) ditemukannya sebab stigma terhadap etnis Tionghoa karena 
adanya wacana etnis Tionghoa adalah pendatang di wilayah Indonesia dan ekslusif. Begitu juga dengan hasil penelitian yang dilakukan oleh Sumardiati (2015) ditemukan sebab kekerasan dan diskriminsasi terhadap etnis Tionghoa karena adanya prsangka bahwa orang Tionghoa dituduh sebagai tukang timbun, hanya mencari untung, dan tidak mempedulikan keadaan masyarakat miskin.

Adapun perbedaan penelitian ini dengan penelitian terdahulu sebelumnya adalah di dalam penelitian ini penulis hanya mengemukakan sebab dan bentuk prasangka berdasarkan pendapat dari beberapa saksi hidup (historis). Sedangkan penelitian terdahulu lebih mengedepankan tentang sebab prasangka berdasarkan adanya relasi atau hubungan antara warga pribumi dan etnis Tionghoa, berdasarkan konflik yang terjadi antar warga pribumi dan etnis Tionghoa serta melihat masing-masing prasangka pribumi dan etnis Tionghoa. Keterbatasan penelitian ini yakni penulis tidak membahas semua aspek namun memiliki perbedaan tersendiri yaitu adanya penelitian mengenai sebab dan bentuk prasangka masyarakat Pariaman terhadap etnis Tionghoa.

Etnis Tionghoa datang ke Pariaman pada tahun 1630 dan diakui sebagai orang Pariaman. Mereka datang ke Pariaman dengan tujuan berdagang (Tanjung,2006). Pada masa kependudukan Belanda etnis Tionghoa mengalami kejayaan, namun masa transisi pemerintahan Belanda ke pemerintahan Jepang pada 1942, keadaan Pariaman sangat tertekan karena kejamnya perlakuan Jepang terhadap masyarakat Pariaman. Pada momen itu etnis Tionghoa mulai mengambil hati Jepang dengan menghalalkan segala cara untuk mempertahankan kekuasaannya dan harta kekayaanya. Masyarakat Pariaman mengetahui hal itu dan berusaha membuat etnis Tionghoa takut dan melarikan diri dengan bersamaan tentara Jepang pada tahun 1945. Selain karena Indonesia sudah menyuarakan kemerdekaannya. Pada tahun 1965 etnis Tionghoa tidak terdaftar lagi sebagai warga Pariaman dan saat tidak satu pun etnis Tionghoa ditemukan di Pariaman. Namun prasangka masyarakat Pariaman masih tetap ada bahkan diwariskan secara turun temurun. Prasangka itu berupa ungkapan verbal seperti Tionghoa jahat, pelit, egois, pengkhianat dan culas.

Keterbatasan solusi yang pernah ada yaitu kebanyakan orang atau peneliti lebih memfokuskan kepada penyebab prasangka dan stereotip diantara kedua etnis, dan bantuk-bentuk prasangka serta peranan identitas nasional dan presepsi ancaman terhadap prasangka kepada etnis Tionghoa. Kemudian kelebihan solusi yang ditawarkan dalam artikel ini adalah peneliti menemukan saksi hidup dalam menentukan sebab terbentuknya prasangka dan bentuk-bentuk prasangka dalam masyarakat terhadap etnis Tionghoa.

Tujuan penelitian ini adalah untuk melihat dan mendeskripsikan bentuk prasangka masyarakat Pariaman terhadap etnis Tionghoa serta dapat bermanfaat bagi masyarakat dalam meminimalisir 
prasangka terhadap etnis yang berbeda. Penelitian ini juga sebagai pengetahuan bagi masyarakat yang belum mengetahui sebab adanya prasangka terhadap etnis yang berbeda dalam masyarakat serta sebagai acuan dalam menciptakan komunikasi lintas budaya yang efektif antar etnik, ras, suku dalam sebuah masyarakat agar solusi yang ditawarkan dapat terealisasikan.

\section{METODE PENELITIAN}

Penelitian ini adalah jenis penelitian kualitatif yang bertujuan untuk mendeskripsikan sebab prasangka masyarakat Pariaman terhadap etnis Tionghoa. Informan dalam penelitian dilakukan dengan purposive sampling yang berjumlah 15 orang saksi hidup. Jenis data yang digunakan dalam penelitian ini adalah data primer dan data sekunder. Pengumpulan data dilakukan dengan wawancara tidak terstuktur dan studi kepustakaan mengenai buku-buku tentang sejarah etnis Tionghoa di Pariaman. Uji keabsahan data dengan menggunakan teknik trianggulasi sumber. Teknik analisis data dilakukan dengan mengumpulkan data, mereduksi data, menyajikan data dan menarik kesimpulan

\section{HASIL DAN PEMBAHASAN}

Bentuk pertama prasangka masyarakat Pariaman terhadap etnis Tionghoa adalah berupa stereotip dalam bentuk ungkapan verbal seperti stereotip etnis Tionghoa sebagai pengkhianat bangsa dan stereotip sebagai etnis yang culas, pelit dan tamak dalam perdagangan. Hal ini diperkuat oleh temuan penelitian terdahulu oleh Gazali (2016) adanya stereotip masyarakat bahwa etnis Tionghoa adalah etnis yang pelit. Hal yang sama juga ditemukan oleh penelitian terdahulu Murdianto (2018) dimana adanya stereotip masyarakat terhadap etnis Tionghoa sebagai etnis economic animal, pelit, rakus dan terlalu perhitungan. Sama halnya dengan temuan penelitian terdahulu oleh juditha (2015) adanya stereotip masyarakat terhadap etnis Tionghoa sebagai etnis yang mau untung sendiri tanpa melihat halal atau haram. Teori yang berkaitan dengan ini adalah bentuk-bentuk prasangka salah satunya stereotip. Stereotip merupakan salah satu bentuk prasangka antar etnik atau ras, orang cendrung membuat kategori atas tampilan karakteristikperilaku orang lain berdasarkan kategori ras, jenis kelamin, kebangsaan, dan tampilan komunikasi verbal dan non verbal (Alo Liliweri (2005).

Sedangkan sebab pertama terbentuknya prasangka masyarakat Pariaman terhadap etnis Tionghoa adalah pengkhianatan yang dilakukan etnis Tionghoa terhadap masyarakat Pariaman dengan menjadi mata-mata Jepang, menginginkan kekalahan terhadap orang Pariaman dan pro terhadap Jepang untuk menjajah orang Pariaman. Hal ini diperkuat oleh temuan penelitian terdahulu oleh Darwis (2013) menyatakan bahwa sebab disharmonisasi masyarakat terhadap etnis Tionghoa adalah adanya warisan dari kondisi sosial pada kolonial yang membeda-bedakan dan mengistimewakan status sosial keturunan Tionghoa yang mengakibatkan warga etnis Makasar yang merasa sebagai pribumi memendam rasa tidak puas terhadap terhadap keturunan Tionghoa yang kemudian melahirkan stigmatisasi. Teori yang berkaitan adalah sebab- 
sebab terbentuknya prasangka dalam masyarakat karena kesan yang menyakitkan atau pengalaman yang tidak menyenangkan yang pernah dialami serta alasan historis (Ahmadi, 2009).

Selanjutnya penyebab terbentuknya prasangka dalam masyarakat Pariaman karena penilaian buruk masyarakat Pariaman terhadap cara berdagang. Berdasarkan sejarah masa etnis Tionghoa di Pariaman (ekonomi) etnis Tionghoa picik dalam persaingan harga. Etnis Tionghoa tidak ingin berbagi ilmu dagang dengan masyarakat Pariaman, monopoli pekerjaan yang hanya mempekerjakan orang Pariaman sebagai buruh kerja saja, suka mengurangi timbangan dan ketamakan etnis Tionghoa yang ingin menguasai toko-toko di Pariaman. Bahkan sawah, ladang, dan kebun kelapa orang Pariaman dari hasil pagang gadai. Menurut penelitian terdahulu oleh Juditha (2015), penyebab terbentuknya prasangka terhadap etnis Tionghoa karena adanya penilaian yang negatif.

Etnis Makasar beranggapan bahwa dalam berbisnis etnis Tionghoa sering bermain curang dan suka menyuap pihak untuk mendapatkan konsesi ekonomi sehingga membuat mereka cepat sukses. Teori yang berkaitan dengan ini adalah sesabsebab terbentuknya prasangka salah satunya masalah ekonomi. Adanya kesadaran masyarakat bahwa kehadiran kelompok atau ras lain dapat mengancam stabilitas sosial dan ekonomi dalam masyarakat serta adanya persaingan yang tidak sehat yang dilakukan oleh suatu kelompok terhadap kelompok lain yang menjurus pada eksploitasi (Zastrow (1989) dalam Liliweri (2005)).

Penyebab prasangka lainnya yaitu perbedaan agama dan sosial kultur. Pariaman merupakan daerah yang mayoritas penduduknya beragama islam dan masyarakat fanatik dengan agama islam yang tidak menerima dan mengizinkan agama-agama lain untuk mendirikan tempat-tempat ibadah agama lain kecuali masjid. Hal ini diperkuat oleh temuan penelitian terdahulu oleh Burhan (2013) bahwa sebab prasangka terhadap etnis Tionghoa karena adanya nilai dan kepercayaan yang dipegang etnis Tionghoa mengenai isu moral dan agama tidak sesuai dengan nilai dan kepercayaan yang dipegang oleh etnis pribumi, nilai sosial (cara bergaul, berteman dan bersosialisasi, dll) yang dipegang etnis Tionghoa tidak sesuai dengan gaya hidup etnis pribumi.

Hal serupa juga ditemukan oleh Sodiq (2016) bahwa sebab kekerasan terhadap etnis Tionghoa karena perbedaan agama masyarakat Pekalongan mayoritas beragama islam dengan tingkat religiusnya tinggi. Teori yang berkaitan dengan ini adalah sebab-sebab terbentuknya prasangka karena perbedaan latar belakng budaya, adanya perbedaan kepercayaan-kepercayaan dan nilainilai yang dipelajari oleh anggota kelompok etnis tertentu dalam berhubungan dengan kelompok etnik lain (Gundykunts (1991) dalam Liliweri (2005). Berbagai diferensiasi yang muncul tersebut juga diteliti oleh Khoiri (2020) yang menemukan bahwa masyarakat Tionghoa perbatasan lebih menyukai dan bergabung dengan sesama etnis. 


\section{KESIMPULAN}

Berdasarkan temuan peneliti dan pembahasan dapat disimpulkan bahwa bentuk prasangka masyarakat Pariaman terhadap etnis Tionghoa adalah stereotip terhadap etnis Tionghoa sebagai pengkhianat bangsa, stereotip sebagai etnis yang culas, pelit dan tamak dalam perdagangan (ekonomi). Sedangkan penyebab prasangka masyarakat Pariaman terhadap etnis Tionghoa adalah adanya pengkhianatan yang dilakukan etnis Tionghoa pada masa pendudukan Jepang Pariaman yaitu dengan menjadi mata-mata atau spionase Jepang, cara berdagang etnis Tionghoa yang dinilai buruk yang mematikan para pedagang Pariaman seperti mengurangi timbangan, tidak ingin berbagi pengetahuan dagang kepada golongan pribumi, dan monopoli perdagangan yang memanfaatkan pribumi sebagai buruh kerja, dan perbedaan sosio kultural. Selain itu penelitian ini telah menekuni bidang ilmu yang sesuai dengan penelitian diantaranya pendidikan multikultural yang mana didalam ini membahas mengenai konsep dasar multikultural yaitu perbedaan yang ada dijadikan sebagai integritas dalam suatu bangsa serta konflik yang disebabkan oleh multikultural dalam masyarakat.

\section{DAFTAR PUSTAKA}

Ahmadi, Abu. 2009. Psikologi Sosial. Jakarta: RINEKA CIPTA.

Dantes, I Nyoman. 2012. Metode Penelitian. Jakarta: Andi OFFSET.

Liliweri, Alo. 2005. Prasangka dan Konflik. Yogyakarta: LkiS
Tanjung, Armaidi.2006. Kota Pariaman

Dulu, Kini Masa Depan.

Pariaman: Bappeda Pariaman

Alfarabi. 2010. - Wacana dan Stigma

Etnis Tionghoa Di Indonesall.

Jurnal An-Nida, 3 (1).

Burhan, Sani. 2013. Prasangka Terhadap Etnis Tionghoa di

Kota Medan: Peran Identitas Nasional dan Persepsi Ancamanl. Jurnal Psikologia, 8 (1), 25-33.

Darwis. 2013. Harmoni dan Disharmoni Sosial Etnis di Perkotaan (Studi Hubungan Sosial Etnis Makasar dengan Etnis Tionghoa di Kota Makassar) ॥. Jurnal socius, 16 (1).

Gazali, dkk. 2016. Stereotip Antara Etnis Tionghoa dan Etnis Jawa Pada Siswa SMA Santa Theresiall. Jurnal At-Turas, 5(1). Juditha, Chiristiany. 2015. - Stereotip dan Prasangka dalam Konflik Etnis Tionghoa dan Bugis Makasarl. Jurnal Ilmu Komunikasi, 12 (1), 87-104.

Khoiri, M., \& Irwan, I. (2020). Nasionalisme Masyarakat di Perbatasan IndonesiaSingapura: Studi Kasus Masyarakat Tionghoa-Batam. Journal of Moral and Civic Education, 4(1), 11-18.

Murdianto. 2018. -Stereotipe, Prasangka dan Resistensinya ( Studi Kasus pada Etnis Madura dan Tionghoa di Indonesiall. Jurnal Qalamuna, 10 (2).

Sodiq, Jayusman, Rahayu. 2016. -Konflik Cina- Jawa di Kota Pekalongan Tahun 1995॥. Journal of Indonesian History, 5 (1). 
Sumardiati, dkk. 2015. -Kerusuhan Pasar Glodok: Studi Kasus Etnis Tionghoa di Kelurahan Glodok Kecamatan Taman Sari Jakarta Barat. Jurnal Publika Budaya, 1 (3), 10-19.

Badan Pusat Statistik (BPS). 2010. Hasil Sensus Penduduk Tahun 2010 tentang Kewarganegaraan, Suku Bangsa, Agama, dan Bahahasa Sehari-hari Penduduk Indonesia. 